\title{
Emotional streaming and transconnectivity: Skype and emotion practices in transnational families in Ireland
}

\author{
REBECCA CHIYOKO KING-O'RIAIN \\ Department of Sociology, National University of Ireland Maynooth, \\ Maynooth, County Kildare, Ireland \\ Rebecca.king-oriain@nuim.ie
}

\begin{abstract}
In this article I explore how transnational families, living in Ireland, use Skype to stay in touch with their loved ones. From 2010 to 2012, data were collected from a purposive, but broad sample of 36 qualitative ethnographic interviews with mixed couples (one partner identifies as Irish and one does not), throughout various parts of the Republic of Ireland. I outline how the use of Skype allows transnational families to create spaces of transconnectivity as they practise simultaneous and ongoing belonging across significant temporal and geographic distances. This affects how people 'do' emotions. These emotion practices often consist not only of 'affect storage' but also of what I call emotional streaming, promoting ongoing interaction over distance, which includes keeping Skype turned on for long periods of time. Through these attempts to try to recreate everyday practices via continuous use of Skype, transnational emotions of love and longing are deintensified.
\end{abstract}

Keywords EMOTIONS, TECHNOLOGY/ICT/SKYPE, COPRESENCE, TRANSNATIONAL FAMILIES, TRANSNATIONAL CARE

In this article, I examine how transnational mixed families give and receive love through using Skype webcam technology to communicate. Many studies of transnational families have focused on the separation that families experience and how they are increasingly using technology (mobile phones, social networking or email) to bridge that socio-spatial distance. The increasing speed of communications and relatively cheap broadband access has meant that digital video communication (webcam, most popularly, Skype) is growing rapidly and in some instances replacing landline and mobile phone communication for many transnational families (Miller and Sinanan 2014). How and why are webcams used in practices of transconnectivity? And how do they shape emotional relationships over distance and time?

By interviewing transnational families residing in Ireland with one Irish partner and a core partner from a different country, I examine the practices and embodied

Global Networks 15, 2 (2015) 256-273. ISSN 1470-2266. (C) 2014 The Author(s) 
experiences of using webcams to understand better the nature of emotions when facilitated and shaped by visual technology. In particular, in an attempt to understand what is distinctive and new about this way of communicating emotions, I focus on Skype webcam use and its impacts on conceptions and practices of transnational caring. Because it is instantaneous, as well as both audial and visual, Skype webcam technology affects the transnational migrants' socio-spatial and emotional relationships both positively and negatively in ways that differ markedly from past means of maintaining transnational relationships (telephone, email and texting).

In 36 ethnographic narrative interviews, I find that Skype webcam technology allows families to create spaces of transconnectivity, simultaneously practising belonging across significant temporal and geographic distances through ongoing technological practices (King-O'Riain 2013), which help them to create and maintain emotional connection. This in turn subtly shapes how people 'do' emotions with multiple platforms (polymedia) of digital technology (Madianou and Miller 2012). In addition to 'emotional banking' and 'affect storage' (Elliott and Urry 2010), these transnational families also engage in what I call emotional streaming, through continuous and ongoing emotional interaction over distance through the webcam. Skype webcam use is not simply used as a voice call with a small visual aspect sitting at the computer screen in a face-to-face headshot. Instead, continuous webcam use is more like 'streaming' a video or movie online and is used as a 'window' into the movement, noise and chaos of everyday life over hours, not minutes. The interviewees here describe their webcam use as helping them cope with and respond to conditions of time and space intensification (Ó Riain 2006), by facilitating strategies to deintensify emotional interaction by leaving the webcam on all day and enabling ongoing long-distance emotional interaction.

\section{Methods}

The data in this article come from an ethnographic narrative interview study of 36 transnational families. The interviews, which were conducted in English between 2010 and 2012, were with same-sex and heterosexual couples and families (ages 26-60) from Ireland, France, Canada, the USA, the UK, Malaysia, India, Sri Lanka, Poland, Zimbabwe and China. The interviewees lived in Ireland in Cork, Kildare, Galway, Tipperary, Dublin and their surrounds. The interviews were digitally recorded and then transcribed. ${ }^{1}$

The research started with the couple/intimate dyad as the initial emotional relationship examined. All couples had one member who described himself or herself as international and not Irish. Eighteen people were interviewed as couples together and 18 as individuals as per the preference of the interviewees - all were a part of a larger transnational family. In total, the interviewees represented participants in 23 heterosexual relationships and four same-sex relationships (three lesbian and one gay male couple). The vast majority of the sample was married (including two of the four same-sex couples married in other legal jurisdictions that allowed same-sex marriage). However, this was not a requirement and interviewees were recruited on 
the basis of what they themselves defined as having a 'long-term relationship' status. Two interviewees have since separated from their partners and failure as well as success in love was discussed. Fifteen people in the sample had children. More women and more non-Irish people agreed to be interviewed, so that Irish men are somewhat under-represented.

Most of the interviewees lived in or around Dublin, in urban and suburban locations, but six were living in rural areas. Some of the Dublin interviewees had past rural experiences. Most of the interviewees identified themselves as middle class though two families described themselves as 'well off' - with high levels of education and employed as academics and architects. Four families described themselves as 'struggling' and seemed to be less well off.

For the most part, the people interviewed did not meet their partners online, but instead in person in various contexts such as studying, working, speed dating, or through friends. Almost all non-Irish people in the sample had made the decision to migrate to (or back to) Ireland in order to stay together as a couple or family. Most described their transnationalism as driven by 'love' - they migrated for love and continued to maintain strong connections transnationally for love.

In the last ten years Ireland has become one of the fastest changing societies in Europe in terms of ethnic and racial diversity, with 17 per cent of the population nonIrish born. ${ }^{2}$ The 2006 census showed 112,898 mixed Irish-non Irish private households (7.7 per cent of all households). This represented an increase from 70,721 in 2002 (CSO 2006: Table 42). Ireland also has a history of emigration and return migration (Ní Laoire 2008); and outward migration is now at its highest rate since 1980. Net outward migration grew from 7,800 in 2009 to 34,500 in 2010 (CSO 2010). This global experience is also clear when many of the Irish-born population in Ireland indicate that they are recently returned from abroad. According to the 2011 census, 19,593 Irish-born people indicated they had returned to Ireland in the last year - mainly from the UK, Australia and the USA (CSO 2012: 32). In many respects, Ireland is a living laboratory on the front line of culturally 'hybrid' global lives, 'global families', and of the growing use of technology (Beck and Beck-Gernsheim 2014).

This research is limited insofar as it focuses on how people said they liked to use Skype and in that it provides only a single snapshot in time of how people negotiated their emotions on Skype. Longitudinal studies, including those focused on the drawbacks of Skype use, are needed to understand better how Skype webcam use changes over time - whether it declines due to the practical constraints discussed below and/or whether it remains an enduring necessity for maintaining emotional ties (for more on this, see Ryan et al. 2014).

\section{Literature}

I turn now to an examination of the three dimensions identified above - the processes of social relations in transconnective space, the practices of emotional streaming within those relations and the intensity (or lack thereof) of the experience of emotions through these practices. 


\section{Transconnective transnationalism}

In transnational families, technology provides a menu of new media options, which 'do not solve the problems of separation within families, but contribute to the transformation of the whole experience of migration' (Madianou and Miller 2012: 2). This may be giving rise to what Conradson and McKay (2007: 168-9) call translocal subjectivities, or as they define them, 'the multiply-located senses of self amongst those who inhabit transnational social fields'. They make the following three points:

- Translocal subjectivities emerge through both geographic mobility and multiple forms of ongoing emplacement.

- The formation of migrant selfhood is usually more closely related to localities within nations than to nation-states. There is affiliation to specific people and places within the nation rather than a more abstract patriotism or sense of nationhood.

- The emotional and affective states that accompany mobility are a key dimension of translocal subjectivities.

Building on Conradson and McKay's notion, I examine one form of transnational communication - webcam use, which facilitates changes in migrants' emotional and affective states, thereby helping to create and sustain translocal subjectivities and ongoing translocal connections. Transnational families are making strong emotional connections over space and time, creating 'translocal affective networks' (Ray 2007: 102). Improvements to mobile and webcam technology have created 'polymedia' 'the new emerging environment of proliferating communicative opportunities' (Madianou and Miller (2012: 8). These have made it possible for people in far-flung locations to see and speak to each other every day without incurring any expense over and above the initial cost of the telecommunications connection. Where letters, phones and cassette tapes kept transnational migrants connected, now there is email (Baldassar 2008) and texting (Uy-Tioco 2007). The advent of cheap telephone calls (some with calling cards) once served 'as a kind of "social glue" connecting smallscale social formation across the globe' (Vertovec 2004: 220). When phones went mobile, they were also found to strengthen close emotional ties through modes such as texting, which worked better to help maintain weak ties (Ling and Stald 2010) as they are suitable for exchanging small bits of news asynchronously and on an intermittent basis. However, global voice traffic is shifting away from fixed landline and mobile phone communication to computer-based, voice over internet protocols (VoIP) such as Skype. Skype constituted 12 per cent of worldwide international voice traffic in 2009 with over 33 billion minutes of use recorded (TeleGeography 2010). ${ }^{3}$

In addition, Skype calls, particularly using webcams, currently do not conform to time limits in the same ways that telephone calls do because of the lack of charges to make video calls. Of the 36 interviewees, 34 used Skype webcams on a regular basis (once a week or more) and 12 indicated that they used it almost every day and often for long periods (more than 15 minutes). With the average mobile phone call lasting 
only three to five minutes (TeleGeography 2010), in part due to cost, interviewees moved onto Skype for longer and often very long (on all day) modes of communication and connection. This made their Skype webcam use fundamentally different from text or email, for there was often no historical textual record of the use. With their communication not monitored or forwarded at will, many interviewees felt that it was closer to the expectations of everyday interaction than telephoning or texting.

Webcam use is visual and aural in real-time - one can see and hear the person with whom one is communicating as well as oneself simultaneously. The sense of belonging and emotional connections to people and places far away can be stronger when the communication is frequent, continuous and for long durations. However, this is not without its limitations (Miller and Sinanan 2014) in terms of selfconsciousness, intimacy, relationship maintenance, and visuality. All of this has implications for how 'sticky' the 'social glue' about which Vertovec (2004) speaks actually is.

International trade and migration are the biggest drivers of international communication. In my sample of interviews, couples often met one another while studying, working, or travelling abroad and then, in many instances, were subsequently involved in long-distance relationships when their visas or jobs ran out. For many couples, this involved a decision to migrate to one or the other's country and culture for emotional, not economic, reasons. This decision was not usually instantaneous and almost always involved communicating, often for extended periods, with partners and close family over long distances and, both before and after migration, being dependent on technology to do so quickly, cheaply and regularly. The ease and availability of technology, for both cheap transport and cheap communications, figured directly in the decisions to migrate. In this sense, micro emotional connections to others and the ease of contact via technology shaped the larger migration patterns and decisions to migrate.

Transnational families have always found ways to communicate their emotions across vast temporal and spatial distances; indeed, the possibility of using technology may have shaped their decisions to migrate. In turn, the migration experience may open up new emotional pathways for transmigrants that are unavailable to them at home. For example, Montes (2013) suggests that it may give them more freedom to transgress prior gendered expectations. Many families discussed here feel that, because their emotional and technological connections are more frequent and last longer than those of people who are separated for shorter periods, their communication patterns and emotional orientations are more global or transnationally focused than those of their domestic counterparts. They regard Skype as a long term, ongoing part of their everyday emotional lives.

This may mean that the space between home and away - 'home/away space' - is a transconnective space in which virtual copresence is the order of the day. In this space, emotional life is increasingly intertwined with a variety of communications technologies, constituting what Hillis (2009: 263) called 'digital affectivity', namely 'the emotional influence on individuals and groups induced by digital media's specific kinds of psychic and experiential effects'. 


\section{Emotional practices}

Much of the literature on transnational practices and emotions has focused on 'care', often in a market setting (Parreñas 2001). Furthermore, classic studies of transnational migration have approached families (Parreñas 2001, 2005; Svašek and Skrbiš 2007) as primary units of analysis, focusing on them as monoethnic units shuttling between two nations or locations, as in such formations as 'parachute kids' (Zhou 1998) or 'astronaut families' (Chiang 2008). Nonetheless, important studies on 'flexible citizenship' (Ong 1998), cultural simultaneity (Levitt and Glick Schiller 2004), and dual citizenship help us to understand the more fluid processes of how people with multiple transnational emotional ties actually live and make meaning in their lives. Newer research on transnational families sees them as produced contingently with migration, globalization and the state influencing micro personal choices of who can love whom (Levitt and Dehesa 2003) and how people create 'global families' (with the insertion of the 'other' in intimate spaces of the family) in many forms, including distant mothering in care chains, surrogacy and intercultural mixed families (Beck and Beck-Gernsheim 2014).

How do such diverse and contingent family forms operate? As technology has expanded, so too has its ability to connect transnational families emotionally. Consequently, since more and more transnational families are using webcams to remain in touch, it is important to examine how using Skype webcams as a means of communication shape and are shaped by the emotional practices and connections of transnational families. My theoretical approach to emotions builds on social constructionist understandings of emotions (Beatty 2005), which comprehend emotions as discourses (words), practices (actions/interactions) and embodied experiences (Baldassar 2008; Ryan 2008; Svašek 2010: 869). All of these are present in webcam use, often in interaction with each other. Emotions are seen as integral to creating a sense of belonging to where you are within local post-migration social support networks (Ryan 2007) but also within transnational support networks via Skype. In this sense, "emotions are a matter not of who we are and what we feel, but of where we are and what is expected of us" (Beatty 2005: 35). But what if 'where' you are is in two places or cultures at once?

I find that, because it is instantaneous, audial and visual, Skype webcam technology affects transnational migrants' socio-spatial and emotional relations both positively and negatively in ways that are markedly different from past means of maintaining transnational relationships (phone, email and texting). I extend the socially constructed concept of emotion in studies of transnational care to focus on those feelings and care beyond mothering that many social actors feel exist (and should exist) outside market forces. The concepts and practices of caring vary and are not static, even in the context of paid for care. For transnational families, this means that national, local and global notions of culture shape digital caring practices, such as using Skype to create, maintain and transform emotional ties (Svašek and Skrbiš 2007).

Emotions can thus form the foundational basis of social ties and the rationale for 
patriarchal family forms. They can motivate decisions to migrate and can shape how people engage in social relations across long distances. In this sense, the data presented here are an illustration of social relations within transnationalism, structured clearly not only by macro-economic forces, but also by micro and highly intimate interpersonal understandings and practices of love. Emotions are not simply convenient resources to be called upon to explain transnational family life; they are constitutive of the transnational family itself (Skrbiš 2008: 242). Transnational families put considerable effort into managing transnational emotions such as loneliness, homesickness, support and obligation (Ryan 2008) and, in emotional discourse and practice, this is often combined with increasing or decreasing emotional attachment to place (Svašek 2010).

But how do people 'do' emotions in transconnective spaces? Elliott and Urry (2010: 28-36) argue that technology usage shapes emotions through what they call 'affect storage'. They argue that life is lived increasingly on the move and therefore people need technology to stay in touch. This then is linked to the digitization of social relationships, but also to changes in how emotions are contained, stored, deposited and retrieved, which itself comes to structure identity. These 'miniaturized mobilities' enter the constitution of the self, which can untie the self from specific locations - identity is then dispersed, adrift, on the move. These 'social ties at a distance depend upon coordination, negotiation with others' (Elliott and Urry 2010: 31) and emotional containment is brought about by digital, wireless technology, which is used to maintain shared histories of intimacy with family (through sharing photos, for example on Facebook or Picassa). Technology then not only facilitates but also contains emotional bonds within it to be used or felt at a later date. While it is reassuring that people can connect with their loved ones at any time, they also feel guilty about being away, which they can then address by spending hours on Picasa organizing photos of their loved ones. They argue that this leads to 'emotional banking': 'the individual might be said to be engaged in an act of "emotional banking" depositing affects, moods, dispositions into the object world and storing such aspects of self experience until they are withdrawn for future forms of symbolization and thinking' (Elliott and Urry 2010: 39).

But are emotions really like data that can be stored and retrieved? What about the times when people use technology not to store emotions but to 'stream' them in real time, as on Skype? Eliott and Urry do not analyse the use of visual technologies that bring the body, face and visual appearance (emotional embodiment) into emotional interaction and practices. To explore this, I look at how people use Skype in their already established love relationships in an attempt to discover how they go about producing and transforming their emotions. Utz (2007) found that important personal matters are still handled primarily in conversation on the telephone instead of through the more impersonal email. But with phone conversations declining both in frequency and duration, it seems that webcam use is one possible step closer in terms of personal intimacy, allowing loved ones constant, everyday access to their lives. Many of the interviewees kept Skype webcams on all day, emotionally streaming themselves into the daily lives and practices of those they love in order to normalize the emotional 
interactions they have - even within a world that is compressing emotion into shorter times and smaller spaces. However, this normalization may bring with it the cost of new obligations and, of course, a new set of limitations.

\section{Experiencing transconnected emotions}

Several new studies are beginning to ask not only how transnational emotional practices are organized technologically (Miller and Sinanan 2014) but also what effect digital technology has on the emotions - particularly in terms of care and 'mothering'. Madianou and Miller (2012), studying Filipina mothers in the UK involved in caring work and their left behind children in the Philippines, found that frequent emotional contact through technology, particularly mobile phone use, allowed mothers separated from their children in the Philippines to 'feel like mothers again'. Because talking to their children on their mobile phones made them feel emotionally connected, the mobile phones themselves came to be a platform for the mothers' existing and increasingly regular emotional expression. However, they did not all express their 'mothering' or love in the same way - some did so intensively, others collaboratively and yet others passively (Peng and Wong 2013). In a study on caring for elderly parents from afar, Baldassar (2008) found that expanded use of email among immigrants who had travelled from Italy to Australia actually increased the need for visits, demands for copresence of varying types, and more information, thus creating closer emotional ties and deeper obligations rather than highlighting the emotional and geographical distance. ${ }^{4}$ In the interviews reported here, for those who could not physically 'be' at home all the time, Skype provided a semi-embodied experience of being connected. In this sense, Skype was considered not perfect, but an improvement on texting and email. This new awareness of the more embodied experience of Skype, being able to see and hear those whom you love, also created an increased need to use other forms of communication to stay in closer contact.

This was gendered in that women tend to prefer visual digital communication in a 'care' situation. Longhurst (2013) found that mothers liked the visual aspect of Skype because they felt that they were better able to assess the 'well-being' of their children if they could see them. This may mean that different types of digital communication have different emotional affordances. So, while mobile phones may help strengthen emotional ties with close family and friends, and while other modes such as texting may help maintain weak ties (Ling and Stald 2010), Skype may be closer to mobile phone contact than texting or email communication and may especially appeal to women. The key element of Skype relative to other forms of communication appears to be its ability to 'normalize' interactions - across space though a rich visual and audial environment and across time due to its low cost and long duration of calls.

\section{Multi-localized transconnectivity}

The families I interviewed were neither disembedded nor deterritorialized (Appadurai 1998), but co-embedded in multiple localities through the use of Skype. One-third of the interviewees reported keeping Skype on all day to create everyday interactions via 
the webcam. By using digital technology (Hillis 1999), they tried to maintain 'copresence' and transconnective space with those with whom they had distant but emotionally strong ties. This was not always at the expense of local ties and often changed over time in a certain location.

Not all the couples had access to the internet, but surprisingly, the majority, even those who were long-term unemployed and/or on limited incomes, prioritized having broadband over a landline or mobile telephones to ensure their access to Skype. Some also accessed Skype in the local public library or on a friend or neighbour's computer. Most, however, had access within their home, many on mobile devices like a phone, laptop or tablet. While the price and cost of buying a computer and getting high-speed internet access was prohibitive for some, once on the internet, usage time did not determine the cost of running Skype webcams (or Facetime on Apple iPhones) off Wi-Fi. Ironically, service 'black spots' in rural, underpopulated parts of Ireland, such as Sligo and Leitrim, often meant that native Irish families had unreliable access to the internet rather than those in developing countries. My sample is not representative of all transnational families in the world, for people are clearly privileged to have access to the internet at all. Nonetheless, Skype and other webcams are increasingly widely used across a broad range of social groups.

Through her constant use of various forms of technology, Kasia, who is in her mid-twenties, is originally from Poland and now works as a clerk in a grocery store, illustrates the multi-localized, ongoing belonging she feels to both Poland and Ireland. She is also connected to other places in which members of her family and friends reside. Kasia tells us about her global family constellation living around the world and how technology connects them.

My closest family is spread around the world. My mother has been living in the USA, in Chicago for five years. My father's been living in London for almost two years, and my brother is finishing studies in Poland, in Rzeszow. And he is concerned where to go now, to whom. He's got a broad choice. And friends are spread as well, in Poland and abroad. That's life ... we have phone calls and SMS (text messaging) and we talk through the internet, Skype, email, Gadu Gadu. ${ }^{6}$ Every day, there is a contact to someone. Now we have internet at home; Skype is always on.

The global cosmopolitan lifestyle to which she alludes is made possible by persistent ethnic digital networks and ethnic communities - settlers who enable mobility. Clearly, the world is a connected place for Kasia's family and there is interpenetration of different places and contexts. There are many national and international spaces and flows in their daily routines and lived experiences. Communication technologies, which are used as a part of the daily pattern of communication, facilitate this transconnectivity and it reveals several things. First, Kasia is a relatively privileged global cosmopolitan, despite her work in the low wage service industry in Ireland. Second, she is oriented towards, and perhaps headed for, many destinations other than Poland or Ireland and is thus situated as a diasporic and multi-destinational migrant. 
This is not the more traditionally held notion of migrants as moving between two poles, but instead is multi-locationally oriented and enabled through digital social networks and the information gained through them. Finally, Kasia sees ethnic diasporic communities and networks as social capital developed through the use of technology, which helps her to gain important information about possible destinations in the future.

Likewise, Ella is an energetic twenty something year-old American living in Dublin. She and her Irish husband, Sean, met when she came to study for a year abroad in Ireland. She describes their first separation when she returned to the USA to finish her degree and her feeling of being both 'here' and 'there' at the same time. Ella describes her ability to have simultaneous attachments to people in different places and how she had to manage being emotionally torn between two places and the people in them. As she explained:

It was hard, it was quite hard and especially I think then when I got back to the US, to try and balance the fact that I was living in Indiana. I was trying to fully commit myself to life there and jumping back into things, yet I felt that part of me was back in Ireland and I was trying to talk to Sean and maybe unsociable hours for one of us because we were six hours apart. So it was really hard in that kind of a way. So I remember tears, we were slowly trying to figure out 'OK how much can we talk a day so we are both happy?' but it is not too much and we don't feel like we don't ever see our friends. I think both of our natural inclinations were just to talk and video chat for ages.

Her interviewer then asked her what would have been too much, to which she replied:

I don't know, I think for us it was a lot, it was more than I think a lot of people would have been happy for, but I think we used to talk, probably for four hours throughout the day. We would talk for maybe an hour in the morning, two hours at night and then an hour somewhere in the day, which is a lot when I think about it now but it was great because we learned so much about how to communicate.

For many, the motivation to purchase and learn to use technology was driven by their desire to communicate more frequently and cheaply with family members from whom they were separated (King-O'Riain 2013). This often meant grandparents purchasing and learning how to use a computer upon the birth of their first grandchild living abroad or couples who first bought and used webcam technology in private households when separated for work. The use of Skype differs from videoconferencing in work settings in that connections are between homes where, both because of the cost and the lack of regulation of this private space, Skype can be on permanently. The usage cost was low in terms of allowing them access to a global and cosmopolitan social network - a transconnective space between homes across borders and distances. 


\section{Affect storage and emotional streaming}

But why do they keep Skype on? Many of my interviewees, primarily women, talked about the strengths of Skype (webcams) over the use of email or other forms of digital communication because it allows you to see to whom you are talking. This ability to see others as well as yourself seemed to lead to closer emotional connections (Miller and Sinanan 2014). Like Longhurst (2013: 664), who found that Skype 'is reorienting mothers' and children's bodies offering a seemingly closer physical and emotional proximity than in the past', more female interviewees spoke of the 'closeness' they felt to their loved ones on Skype. They described a physical need to see their loved ones. Technology connects them, not as a depository for emotions but as a medium through which to stream emotions and as a way to 'see' family. Callum, a computer scientist in his mid-twenties, speaks about his Canadian girlfriend and her use of Skype to talk to her family back in Canada. Callum explains that he and his girlfriend do not put their emotions into the computer to be retrieved and relived later because Skype offers little capability to be replayed after the fact. For them, it is the ability to see and interact with loved ones far away in real time that matters. He explains:

It is important for my girlfriend. She needs to 'see' her family. See that they are well. What she really wants is to reach out and hug them, but she can't - so this is the next best thing. She really needs to see them on Skype. I don't. For me, the phone is enough.

Likewise, Susan, in her thirties and born in the UK but now living in Tipperary with her Irish husband and their new baby, talked about communicating with her parents in the UK about her daughter's growth. She stressed several times to me how important Skype as a visual form of communication was for young children.

I will Skype more than the phoning because then they [her parents in the UK] can see us. I think the visual side, particularly with children, is really important and they haven't seen her since she has been able to sit up and everyone is longing to see that. And she likes swimming now and they haven't seen her swimming.

To the interviewer's question of 'and do you think your daughter would be close to your parents?' Susan replied:

I really hope so and I know Mum keeps saying, last time we met up she said, 'I am not sure that she remembers who I am.' And I was saying, 'I am sure she does, she will do.' And that is the one thing that worries me that she won't see them enough that she will remember who they are, so I feel it is important for me to tell her things about them. I just hope that she will get it as she gets older. 
The interviewees were very clear that they were using Skype as the 'next best thing' to being there. They did not want their loved ones to forget what they looked like and they especially wanted small children to be able to recognize them when they next met in person. They worked to create a copresence via Skype as a form of virtual embodiment; they did not expect Skype to replace actual physical contact, but rather to provide a stand in until they could be physically together again. Skype allowed the interviewees some of the bodily aspects of face-to-face communication like sight and sound, but without others such as smell and touch. One couple interviewed on a radio programme who met on Skype said that they eventually had to meet in person 'because you can't smell someone on Skype' (RTÉ 2012).

Again, the use of webcams transformed Ella and Sean's relationship when they were apart. As Ella explains:

And it was funny, the video chat really changed things and I at first was like, 'oh I don't need a webcam, it is not a big deal,' so I didn't get one and he didn't have one and we kind of thought it was no big deal. And my mom, who knew me, arranged secretly with him to get me a webcam sent to my dorm and to get him to buy one because she was like, 'I think she will really like this.' And it actually made things a lot better, I don't know why, seeing him in person. We could sit there and like if I had a paper to write, I could write a paper and he could write his Ph.D. and we would kind of be chatting and have each other on a small video screen and it was a bit more casual. I think most of the time we did just talk, we didn't do other work, but something about seeing him made it that bit nicer and more personal. I did like that.

Ella felt that using the webcam to communicate was different from email in that it enabled you to see one another. It was more than just storing up news and emotions, which they did on email to share with Sean later, but in fact, it was spending time with Sean and seeing him. She explains:

Emailing we didn't do very much, we did a few of them definitely. I just think it was more personal, something about being able to see where the other person was and it was very hard to explain it. It was just about that part where you are in your life and you have seen the other person in their normal life and you can talk about things and you can have that kind of facial reaction and the pauses and the silences that you couldn't have over a phone. You'd be there going, 'are you listening to me?' Whereas when you see him you think, OK he is listening to what I just said, he is just thinking about it and you could actually gauge a reaction a bit better. I have to say it was a lot better because the first four months when we went without the webcam it was really hard.

In another family, Elena (who is Italian) and John (her Irish husband), now living in Ireland with their five-year-old son, describes how her parents Skype them on Sundays to speak Italian to their only grandchild. When their son did not want to 
speak, or if he got bored talking on Skype, the grandparents in Italy would tell the parents in Dublin just to 'point the laptop in his [the grandchild's] direction' and they would be happy to watch him doing whatever he was 'doing naturally'. They laughed as they told me how this ended up with Elena's parents in Milan watching their grandson watching TV in Ireland, via Skype. The grandparents continued to chat in Italian with their grandson, without the parents present, about the programme (which happened to be broadcast in the Irish language) and asked him over and over again to translate into Italian what the TV cartoon characters were saying. So, while the grandparents could not provide actual hands-on child supervision for long periods of time because they were not physically present (Ryan 2007), they could 'watch' him for short periods of time while, for example, his mother took a shower. For this family, as for many others discussed above, the goal was not just 'to store up emotions' but to try, through the constant use of Skype, to recreate everyday interactions, to maintain the grandchild's ability to converse in Italian and to 'spend time together casually' in other words, they were 'streaming' their emotions into each other's daily lives.

\section{Digital technology and emotional deintensification}

Many in the sample used emails primarily to leave messages for future retrieval or for loved ones in other time zones to find first thing in the morning. However, they preferred Skype webcams for 'just hanging out' with loved ones, watching movies together, having meals together, even singing and praying together. They talked about how Skype in particular could transcend long distances, but not always time zones and they used it to try to recreate a more natural 'face-to-face like' conversation and interaction, thus dampening down the emotional content they felt with other technological means of communication. Some did not spend most of their time on Skype sitting in a headshot facing those with whom they were communicating, but instead kept Skype on for long periods - using it more as a window into the world of their loved ones - with people wandering in and out of the screen, talking and at times just enjoying the silence together.

Skype was not perfect; many complained of broken connections, frozen images on screen, lack of eye contact (due to the positioning of the camera), and the problem of multiple voices talking all at once making it difficult to hear. But almost all said that it was an improvement over the telephone and their persistence in using Skype seemed to be an attempt to reduce the intensity of the emotional interaction by making it an everyday occurrence, as if they were together in the same room. Instead of trying to pack a year's worth of emotional interaction into one visit, Skype offered the chance to try to string out and spread the emotional content over a longer period. Again, Susan, from the UK, who lives in southwest Ireland, explained the impact that she thinks technology is having:

She [the baby] has changed so quickly and I know in particular my mum really misses me. I know that and I think the way I deal with it is I kind of try not to think about that too much because my sister lives five minutes around the 
corner from them and I always say to my husband, that is the one thing I really miss about where we are is that I can't pop in for a cup of tea. And when we go to stay, and you probably know this, it is for a concentrated amount of time so it is very intense and you sort of miss that being able to pop in and have a chat just for half an hour and get on with the rest of your life. It is just very intense.

In her challenge and isolation of being a new mother, Susan freely admits to being homesick and missing her parents, especially her mother. She is trying to 'cram' all her emotional connections, news and feelings into the short time they are actually together. She uses Skype to supplement her personal visits home, and says it helps her to maintain contact, but in a less intense, more everyday kind of way. When I asked her about the content of what they talk about on Skype she explained:

It is nice, it is generally the kind of things they have been up to, the kind of things you would chat about over a cup of coffee and so you do get a sense of that. I am not great on the phone. I am the kind of person [who] prefers to sit in front of someone, you can pick up on all the cues and I think with email you don't get that in the same way. And also with email, I mean I probably spend too much time rereading emails before I send them because I am conscious if you write something very quickly you can say something that doesn't give off the right thing and when the person picks it up they might misinterpret it.

Through her continual Skype calls to her parents in the UK, Susan is trying to close the distance between them and recreate the kind of 'regular' life associated with having a chat over a cup of tea, or calling in casually.

She says that she 'loves Skype' and that it is a lifesaver because she cannot fly back to the UK as much as she would like to and, for her daughter's sake, she wants to maintain as much contact as possible with her parents.

Most of the interviewees recognized the bodily limits of copresence and acknowledged experiencing a reflexive moment in which they saw how technology could structure their relationships and emotions. This was particularly clear when the time came to hit the 'end call' red button and disconnect from their loved ones afar, as in the following exchange I had with Ella.

On asking her how she felt about hitting the red button, she replied:

Yes it was hard, but then a lot of times it was nice too because I could go all the way like, I am going to get in bed and say goodnight to you and then turn off the webcam so the last thing I see at night is still you so it is as if you are still together.

I then asked her if she felt as if they were really together and she answered:

I did and I suppose it was great because we were living such separate lives and in a way we were having such fulfilling great experiences and then we could 


\section{Rebecca Chiyoko King-O'Riain}

spend all this time talking about it so it was as if he was there with me experiencing it all. Because we used to tell each other all of our days, he said he never was good at talking on the phone or talking about his days, but then once we got into that long distance thing he was forced to not just say, 'oh yeah I had a good day.' But to go and say, well what did I actually do?

Susan, on the other hand, admitted that she used Skype to mediate her emotions and try to ease the sense that there was something important that was 'missing' from her life in Ireland.

But I found for Skype when she was a baby it was amazing; at least they [her parents in the UK] got to see her [her daughter in Ireland]. I didn't feel so guilty that I am in a different country, like nearly every day we were on it, but now not as much.

While keen to use Skype to stay in touch with loved ones, it was not seen as the only way to do so. One Spanish interviewee separated for a while from her long-term Irish boyfriend commented about Skype and the emotional obligations that it can create:

There is clearly a limit to it. At the very beginning when you are first separated for a while it really helped, well actually yes and no because then you become dependent on the phone call. I have been in a long distance relationship before and we would call each other once every five or six days because it was expensive and things like that. So if you don't hear from somebody for a few days you won't imply that there is something wrong or he doesn't love me anymore or things like that, but in this case you become very dependent because you have the assumption that of course he should be Skyping because he can.

The need to hear from a loving partner increased on Skype, but the content of the emotional communication seemed to become less intense with use over longer periods of time. It was often impossible to keep small children in front of the webcam (usually seated) for any length of time. More often than not, my interviewees got up and wandered around, often not in the screen shot at all. They kept an eye on Skype and spoke from time to time often chatting while cooking, watching TV, or caring for children, with others on Skype. This assumes though that people are able to Skype all day or all the time, which clearly many, due to work and other commitments or access issues, may be unable to do. Nonetheless, having Skype on, particularly for longer periods of time, meant that Skype evened out the peaks and troughs of emotional interaction and, for many, this more closely approximated emotional interaction in real life. Their insistence that this made it easier to have more 'everyday life' interactions on Skype was one of the driving factors for getting and using Skype, some every day, even from afar. 


\section{Conclusion}

Conventional views of transnational families tend to regard their social and spatial relationships as focused on separation and distance and the technology, such as email, as used intermittently to store emotions across time zones. Although far from perfect, the increasing use of webcams, particularly on mobile devices, allows transnational families to keep Skype turned on all the time if they so wish, thereby changing their experience of transnational living. The data from my interviews with transnational families in Ireland suggest three extensions to the conventional view of transnational families. In each case, I identify a set of social relations, practices or experiences that differ from those using the phone, email or other types of communication. First, transnational families are not emotionally disembedded, but co-embedded in localities facilitated by the increasing use of technologies such as Skype. The use of Skype webcam technology allows them to create spaces of transconnectivity, which ongoing, not intermittent, real-time visual communications characterize. Second, using Skype changes the way in which people express their emotions. They not only store them up, but also engage in practices of emotional streaming. Third, this leads to emotional experiences that do not fluctuate as intermittent ICT communications generate 'peaks and troughs' of emotional interaction with loved ones. Instead, by facilitating ongoing emotional streaming, the use of technology enables people to deintensify their feelings and thus normalize their daily emotional interactions.

\section{Acknowledgements}

Many thanks to Mirca Madianou, Minelle Mahtani, Helen Marrow, Mary Gilmartin, Sean Ó Riain and the anonymous reviewers for their helpful comments and suggestions.

\section{Notes}

1. The project complies with best professional ethical practice and was approved by the National University of Ireland Maynooth Ethical Approval Committee. All interviewees gave their express consent to be interviewed.

2. See http://www.irishtimes.com/newspaper/breaking/2010/0727/breaking38.html

3. See www.telegeography.com/assets/website/images/maps/global-traffic-map-2010/globaltraffic -map- 2010-x.jpg

4. Baldassar (2008) identifies four types of shared copresence - virtual, proxy, physical and imagined.

5. I would like to express my sincere thanks to Pierce Richardson and Brenda Farrell for their research assistance.

6. The interviewee told me that 'gadu gadu' means 'chitchat' in Polish and is the name of a Polish language instant messaging system.

\section{References}

Appadurai, A. (1998) Modernity at large: cultural dimensions of globalization, Minneapolis, MN: University of Minnesota Press. 


\section{Rebecca Chiyoko King-O'Riain}

Baldassar, L. (2008) 'Missing kin and longing to be together: emotions and the construction of copresence in transnational relationships', Journal of Intercultural Studies, 29 (3), 247-66, doi: 10.1080/07256860802169196.

Beatty, A. (2005) 'Emotions in the field: what are we talking about?', Royal Anthropological Institute, 11 (1), 17-37, doi: 10.1111/j.1467-9655.2005.00224.x.

Beck, U. and E. Beck-Gernsheim (2014) Distant love, Cambridge: Polity Press.

Chiang, L. N. (2008) “"Astronaut families": transnational lives of middle-class Taiwanese married women in Canada', Social \& Cultural Geography, 9 (5), 505-18, doi: 10.1080/ 14649360802175709.

Conradson, D. and D. McKay (2007) 'Translocal subjectivities: mobility, connection, emotion', Mobilities, 2 (2), 167-74, doi: 10.1080/17450100701381524.

CSO (Central Statistics Office) (2006) Census 2006 - vol. 4: usual residence, migration, birthplaces and nationalities, Dublin: CSO.

CSO (Central Statistics Office) (2010) Population and migration estimates, April 2010, Dublin: CSO (printed 21 September 2010).

CSO (Central Statistics Office) (2012) This is Ireland: highlights from census 2011, Dublin: CSO, available at: www.cso.ie/en/media/csoie/census/documents/census $2011 \mathrm{pdr} /$ Census, 2011,Highlights,Part,1,web,72dpi.pdf.

Elliott, A. and J. Urry (2010) Mobile lives, London: Routledge.

Hillis, K. (1999) Digital sensations: space, identity, and embodiment in virtual reality, Minneapolis, MN: University of Minnesota Press.

Hillis, K. (2009) Online a lot of the time: ritual, fetish, sign, Duke, NC: Duke University Press.

King-O'Riain, R. C. (2013) 'Transconnective space, emotions and Skype', in T. Benski and E. Fisher (eds) Internet and emotions, London: Routledge, 131-43.

Levitt, P. and R. de la Dehesa (2003) 'Transnational migration and the redefinition of the state: variations and explanations', Ethnic and Racial Studies, 26 (4), 587-611, doi: 10.1080/ 0141987032000087325.

Levitt, P. and N. Glick-Schiller (2004) 'Conceptualizing simultaneity: a transnational social field perspective', International Migration Review, 38 (3), 1002-39, doi: 10.1111/j.17477379.2004. tb00227.x.

Ling, R. and G. Stald (2010) 'Mobile communities: are we talking about a village, a clan, or a small group?', American Behavioral Scientist, 53 (8), 1133-47, doi: 10.1177/ 0002764209356245.

Longhurst, R. (2013) 'Using Skype to mother: bodies, emotions, visuality, and screens', Environment and Planning D: Society and Space, 31 (4), 664-79, doi: 10.1068/d20111.

Madianou, M. and D. Miller (2012) Migration and new media: transnational families and polymedia, London: Routledge.

Miller, D. and J. Sinanan (2014) Webcam, Cambridge, UK: Polity.

Montes, V. (2013) 'The role of emotions in the construction of masculinity: Guatemalan migrant men, transnational migration and family relations', Gender and Society, 27 (4), 469-90, doi: 10.1177/0891243212470491.

Ní Laoire, C. (2008) 'Complicating host-newcomer dualisms: Irish return migrants as homecomers or newcomers?', Translocations: Migration and Social Change, 4 (1), 35-50, available at: www.translocations.ie/docs/v04i01/Vol_4_Issue_1_Caitriona_Ni_Laoire.pdf.

Ong, A. (1998) Flexible citizenship: the cultural logics of transnationality, Durham, NC: Duke University Press.

Ó Riain, S. (2006) 'Time-space intensification: Karl Polanyi, the double movement, and global informational capitalism', Theory and Society, 35 (5-6), 507-28, doi: 10.1007/s11186-0069016-7.

Parreñas, R. S. (2001) Servants of globalization: women, migration and domestic work, Palo Alto, CA: Stanford University Press. 
Parreñas, R. S. (2005) Children of global migration: transnational families and gendered woes, Palo Alto, CA: Stanford University Press.

Peng, Y. and O. M. H. Wong (2013) 'Diversified transnational mothering via telecommunication: intensive, collaborative, and passive', Gender and Society, 27 (4), 491-513, doi: $10.1177 / 0891243212473197$.

Ray, L. (2007) Globalization and everyday life, London: Routledge.

RTÉ (Raidió Teilifís Éireann) (2012) 'Because you can't smell someone on Skype', Documentary on One (radio documentary), 5 January 2012, available at: http://www.rte.ie/ radio1/doconone/the-curious-ear-doconone-skype-love.html.

Ryan, L. (2007) 'Migrant women, social networks and motherhood: the experiences of Irish nurses in Britain', Sociology, 41 (2), 295-312, doi: 10.1177/0038038507074975.

Ryan, L. (2008) 'Navigating the emotional terrain of families "here" and "there": women, migration and the management of emotions', Journal of Intercultural Studies, 29 (3), 299-313, doi: 10.1080/07256860802169238.

Ryan, L., A. Klekowski von Koppenfels and J. Mulholland (2014) “"The distance between us": a comparative examination of the technical, spatial and temporal dimensions of the transnational social relationships of highly skilled immigrants', Global Networks, Early View article (online version published before inclusion in an issue), doi: 10.1111/ glob.12054.

Skrbiš, Z. (2008) 'Transnational families: theorising migration, emotions and belonging', Journal of Intercultural Studies, 29 (3), 231-46, doi: 10.1080/07256860802169188.

Svašek, M. (2010) 'On the move: emotions and human mobility', Journal of Ethnic and Migration Studies, 36 (6), 865-80, doi: 10.1080/13691831003643322.

Svašek, M. and Z. Skrbiš (2007) 'Passions and powers: emotions and globalization', Identities: Global Studies in Culture and Power, 14 (4), 367-83, doi: 10.1080/10702890701578415.

TeleGeography (2010) 'Global traffic map 2010', online resource, available at: www.Telegeography.com/assets/website/images/maps/global-traffic-map-2010/globaltraffic-map-2010-x.jpg.

Utz, S. (2007) 'Media use in long-distance friendships', Information, Communication \& Society, 10 (5), 694-713, doi: 10.1080/13691180701658046.

Uy-Tioco, C. (2007) 'Overseas Filipino workers and text messaging: reinventing transnational mothering', Continuum: Journal of Media \& Cultural Studies, 21 (2), 253-65, doi: 10.1080/103 04310701269081.

Vertovec, S. (2004) 'Cheap calls: the social glue of migrant transnationalism', Global Networks, 4 (2), 219-24, doi: 10.1111/j.1471-0374.2004.00088.x.

Zhou, M. (1998) "Parachute kids" in southern California: the educational experience of Chinese children in transnational families', Educational Policy, 12 (6), 682-704, doi: $10.1177 / 0895904898012006005$. 